\title{
Adapting to the Physical Changes of Aging with COPD
}

\author{
Gail Low', Donna Wilson', Michael Stickland ${ }^{2,3}$, Carolyn Ross', Eric Wong ${ }^{3}$ \\ ${ }^{1}$ Faculty of Nursing, University of Alberta, Edmonton, Canada \\ ${ }^{2}$ G. F. MacDonald Centre for Lung Health, Covenant Health, Edmonton, Canada \\ ${ }^{3}$ Division of Pulmonary Medicine, University of Alberta, Edmonton, Canada \\ Email: gail.low@ualberta.ca
}

Received 21 June 2015; accepted 28 July 2015; published 31 July 2015

Copyright (C) 2015 by authors and Scientific Research Publishing Inc.

This work is licensed under the Creative Commons Attribution International License (CC BY). http://creativecommons.org/licenses/by/4.0/

(c) $\underset{\mathrm{EY}}{\mathrm{E}}$ Open Access

\section{Abstract}

The prevalence of Chronic Obstructive Pulmonary Disease is growing, and people are living with this disease well into older age. Little is known about how people with Chronic Obstructive Pulmonary Disease adapt to aging, particularly the physical changes of aging. According to the Identity Process Theory, people are inclined to attribute age-related changes in physical functioning to a transitory state of health, but not their physical health or appearance. Attributing one's physical functioning to aging itself makes people believe that they are physically "old" and enhances negative affect. We tested the Identity Process Theory using secondary physical functioning and physical health data collected from 87 pulmonary rehabilitation program participants with Chronic $0 b$ structive Pulmonary Disease (age range $=47$ - 82 years of age). Transient health states were participants' 6-Minute Walk Distance and perceived breathlessness during a time-limited exercise test using the Borg Rating of Perceived Exertion Scale. Participants' age-related changes in physical functioning were attributed to walk distances and their physical health to the physical changes of aging $\left(X^{2}=18.55, d f=10, p=0.05 ; G F I=0.95 ; R M S E A=0.10\right)$. These attribution patterns were replicated in the Borg Rating of Perceived Exertion model $\left(X^{2}=13.34, d f=10, p=0.21\right.$; $G F I=0.96$; $R M S E A=0.06$ ). The attributing of age-related changes in physical functioning to either transient health state circumvented their propensity for negative affect. Our findings are discussed in relation to maintaining physical functioning and general physical health promotion among Pulmonary Rehabilitation Program participants with Chronic Obstructive Pulmonary Disease.

\section{Keywords}

Aging, Physical Identity, Pulmonary Rehabilitation, COPD, Mental Health 


\section{Introduction}

People living with Chronic Obstructive Pulmonary Disease (COPD) typically experience significant declines in physical functioning that interfere with everyday activities [1] [2]. People typically have COPD for many years, if not decades [3] [4]. Many people with COPD are thus adapting to the physical declines associated with aging itself. According to the Identity Process Theory (IPT), people are most vigilant and are troubled by age-related changes in their physical functioning as opposed to their physical health or appearance [5] [6]. People tend to attribute age-related changes in physical functioning to transient states of health as opposed to physical aging [5] [6]. In this way, limitations in physical functioning are seen as temporary and this circumvents negative affect. We tests the IPT using data collected in an earlier study of attitudes to aging among 87 pulmonary rehabilitation program (PRP) participants living with COPD at a variety of ages [7].

People living with COPD typically have, through the test of time or perhaps trial and error, devised a wide range of psychological strategies to adapt to declines in their physical functioning that make performing everyday activities difficult. People with COPD report being vigilant about prioritizing activities [1] [2] [8] [9], and focusing on what they can do rather than cannot do [2] [10]. Deliberately ordering and separating activities into different times of day or different days is another strategy [11] [12]. Others decide to be active only within close proximity to home [13] and pursue sedentary or distracting activities such as music appreciation and craft work [14] [15].

People with COPD are characterized as pro-active self-managers of their illness [16]. However, declines in physical functioning that interfere with everyday activities typically increase as this disease progresses [3] [4]. People with COPD thus may acknowledge "giving in" or accepting difficulties in physically performing everyday activities [17]. Other strategies include seeing COPD as one's fate in life [13] and surrendering to COPD while connecting with a divine or higher power [15]. Others realize that ongoing change [10] and needing help from others [18] are essential in everyday life. People with COPD also draw upon past experiences for strength [17] [19] and make lists of who to call upon when everyday activities become unmanageable [2] [12].

Because people live a long time with COPD, they chronologically and physically age alongside this disease. A hallmark challenge of aging is not being preoccupied with physical aspects of the self, including everyday activity limitations [20]. Being able to carry out activity routines and taking part in hobbies and interests are an important part of aging individuals' identity [21]. Hoped-for selves in older age have been defined as mobile selves while feared-selves are physically limited in taking part in activities and hobbies [22]. From middle-age onward, needing help or care from others has been associated with thinking of older age as a time of physical loss [23]. Physical illnesses can enhance the awareness of negative physical changes with aging among people in their 50s [24]. Older adults living with a serious progressive physical illness equate aging with limited physical abilities [25].

COPD is a serious progressive physical illness most commonly diagnosed in the 5th decade of life [3] [4]. People with COPD experience considerable fear and anxiety over their physical limitations [26] [27]. They speak of a body that is physically limited and lacks strength [8]. Mobility itself is seen as a marker of the usefulness of one's body [2]. There is some evidence indicating that people with COPD not only worry about continuously deteriorating physical abilities, they also report having a diminished physical appearance. Female PRP participants between 45 - 81 years of age have reported that people stare at them when they appear breathless in public places [28]. Men and women in their 50s, 60s, and 70s have reported being quite conscious of weight loss and shrinkages in posture [11]. People living with COPD well into their 70s and 80s also remark that they are acutely aware of living with a decaying body [19]. There are a few COPD-specific studies directly focusing on perceptions of aging. Among adults 50+ years of age, positive perceptions of aging predicted the odds of dying over a 23 year period [29]. People in their 70s and 80s have described tasks of everyday living as a hardship because of the physical limitations of COPD and a physically aging body [19]. COPD-specific activity limitations have also been found to provoke negative thoughts about physical aging as early as midlife [7]. COPD has also been defined an age-dependent disease with a view to developing anti-aging molecules to combat deteriorating pulmonary function and inflammation [30]-[32]. Very little is known about how people with COPD adapt to physical aging.

The IPT is a theory of how people adapt to the physical changes of aging. According to the IPT, physical functioning, health, and appearance are key aspects of peoples' physical identity [5] [6]. When people are in their 40s, they start becoming vigilant about age-related changes in their physical identity [6]. However it is age-related changes in physical functioning that pose the biggest threat to how people see themselves aging 
physically. Age-related limitations in physical functioning make people begin to believe that their body is less capable and that they are physically "old" [6]. Accordingly, people tend to respond to age-related limitations in physical functioning using the identity assimilation process [33]. Identity assimilation is the process of attributing age-related changes in physical identity to a more transient state of health, not to the physical changes of aging [5]. Identity assimilators crave a youthful physical identity [34]. Transient health attributions psychologically distance people from their own process of aging [5] [6]. Transient health states are temporary. The physical changes of aging are not.

Identity accommodation is the process of attributing age-related changes in physical identity to the physical changes of aging as opposed to transient health states [6]. Identity accommodators readily acknowledge that their own aging process has asserted itself [6] [33]. Even when age-related changes in physical identity are small, identity accommodators dwell upon thoughts of their body being less capable and being physically "old" [5]. People who use the accommodation process alone are thus prone to negative thoughts about the physical changes of aging and to negative affect [5] [6]. People prefer to mentally process age-related changes in their identity in a way that helps them maintain a positive mindset as it is psychologically painful to acknowledge personal limitations [34]. The identity accommodation process is used only when things become unmanageable [5] [6].

The IPT is relevant to people with COPD because of its emphasis on physical functioning. People with COPD are also prone to negative affect, particularly in terms of symptoms of depression and anxiety [35]-[37]. The IPT also purports that people begin to think about age-related changes in their physical identity around midlife. Similarly COPD is most commonly diagnosed when people are in their 50s and 60s; however screening is recommended when people are in their 40s, particularly for current and ex-smokers [3] [4]. More than 700,000 Canadians 35+ years of age have COPD based on the clinical symptoms that they report to family physicians [4]. Although COPD is often thought of as being prevalent in old age, many people in their forties and fifties are diagnosed with moderate to severe COPD [8] [17]. COPD-specific mortality rates rapidly increase after age 75 [4]. A growing number of people are aging with this COPD.

Understanding how people with COPD negotiate their physical limitations in relation to aging is important for health care providers, especially Pulmonary Rehabilitation Program (PRP) practitioners. Along with family physicians, PRP practitioners are often primary care providers for people living with COPD at a variety of ages. The aim of this study was to investigate whether PRP participants who were living with COPD from midlife onward would use the attribution processes outlined in the IPT. Accordingly we asked: 1) Which age-related changes in physical identity would people living with COPD attribute to a transient health state versus the physical changes of aging?; and 2) If transient health state attributions are made, does this circumvent negativity toward the physical changes of aging and the propensity for negative affect?

\section{Methods}

We conducted a secondary analysis of data collected in an earlier study of attitudes to aging among 87 PRP participants between the ages of 47 and 82 who were living with COPD [7].

\subsection{Participants \& Sampling}

Participants in the original study were recruited from the Breath Easy Program (BEP) within the G. F. MacDonald Centre for Lung Health, a Covenant Health PRP in Edmonton, Alberta. The BEP starts every 8 weeks and enrolls about 250 COPD patients each year. Study recruitment took place over an 8-month period, with enrollment on the last day of each BEP so as to not interfere with the program. BEP participants completed a wide variety of screening tests throughout their program, including the SF-36 [38] and 6MWD or 6 Minute Walk Distance [39] test, and the BRPES or Borg Rating of Perceived Exertion Scale [40] [41].

On the last day of each 8-week BEP program, a presentation about the study was made to 166 potential participants. BEP participants were informed that they were being asked to complete an aging questionnaire and consent to releasing information about their personal and clinical characteristics, and their SF-36 and SGRQ scores to the researcher. The 87 participants who took part in the study met the following criteria: a) a physician-confirmed diagnosis of COPD; b) able to speak and read English; and c) had no other illnesses preventing them from taking part in the BEP. Research ethics approval was obtained from the University of Alberta Health Ethics Review Committee. 


\subsection{Measures}

\subsubsection{Physical Functioning}

Participants' physical functioning was assessed using the Physical Functioning scale of the SF-36 Physical Component [38]. In the 10-item Physical Functioning scale, respondents are asked to rate their limitations during vigorous and moderate activities. They also rate the following activities: including lifting and carrying groceries, climbing several flights of stairs versus one flight of stairs, bending and kneeling, walking one mile, walking several blocks versus one block, and dressing and bathing. Each item was recorded so that its 3-point Likert scale response categories were a) "yes, limited a lot”; b) “yes, limited a little”; and c) "no, not limited at all”.

\subsubsection{Physical Health}

Participants' physical health was assessed using the 5-item General Health scale of the SF-36 Physical Component [38]. In the 5-item General Health scale, respondents are asked to: 1 ) rate their health. Item 1 was recorded so that its 5-point Likert scale response categories ranged from "poor" to "excellent". The other items ask whether participants: 2) seem to get sick a little easier than other people; 3) are as healthy as anybody they know; 4) expect their health to get worse; and 5) perceive their health to be excellent. Items 2 - 5 were recorded to yield the following 5 response categories: a) "definitely true”; b) "mostly true”; c) “don’t know”; d) "mostly false”; and e) "definitely false".

\subsubsection{Negative Affect}

Negative affect was measured using the Mental Health scale scores from the SF-36 Mental Component [38]. The items in this scale ask about: 1) being nervous; 2) being down in the dumps; 3) feeling calm and peaceful; 4) feeling downhearted and blue; and 5) being a happy person. Items 4 and 5 were reverse coded to ensure 6-point Likert scale response categories ranging from a) "all of the time"; b) "most of the time"; c) "a good bit of the time"; d) "a little of the time"; and e) "none of the time".

All scale scores are calculated using scale-specific linear z-transformation equations [38]. These z-scores are multiplied by 10 and this product is added to 50 . The separate norming of SF-36 scales permits researchers to use these scales separately. Normed scale scores allow researchers to compare their own score distributions to those of adults of all ages living with chronic lung disease in the United States general population [38]. For Physical Functioning the expected mean is 37.82 with an expected score range of 15 - 58. The General Health scale expected mean is 38.60 and the expected range is 17 - 64. The Mental Health scale expected mean is 44.74 and the expected range is 14 - 65. Every 1-point difference from the expected mean equals one-tenth of a standard deviation.

BEP master files that we had access contained only domain-specific SF-36 scores. This prevented us from computing reliability coefficients. The general population reliability estimate for the Physical Component General Health scale is $\alpha=0.81$. For Physical Functioning and for Mental Health, these are 0.94 and 0.83 , respectively [38]. A Cronbach's alpha of 0.78 for General Health, 0.91 for physical functioning, and 0.89 for Mental Health has been reported among community-dwelling persons with COPD [42].

\subsubsection{Physical Changes of Aging}

Participant's perceptions of the physical changes of aging were captured using the Attitudes to Aging Questionnaire or AAQ [43]. The 24-item AAQ captures the aging individuals' perceptions of the physical and psychosocial aspects of their own aging process. We used the 8-item Physical Change domain as it focuses on the physical changes of aging. Items in this particular domain are measured on a 5-point Likert scale ranging from "strongly disagree" to "strongly agree". There are three items asking about whether respondents feel at ease with aging, don't feel old, and if their identity is not defined by their age. The other five items pertain to whether respondents have enough energy, whether their health is better than expected for their age, whether physical health problems don't hold them back, and the regularity and the important of exercising. The Physical Change domain is scored by adding responses to all 8 items thus domains scores range from 8 - 40. Higher scores reflect a more positive perception of the physical changes of aging. The Cronbach's Alpha coefficient for the Physical Change domain in this study was $\alpha=0.72$. The internal consistency of the Physical Change domain in others' studies has ranged from 0.68 and 0.76 [44]-[46].

\subsubsection{COPD Severity}

We accounted for participants' COPD severity because physical functioning tends to get worse as COPD sever- 
ity increases [4]. All 81 of our participants had their COPD severity tested as part of the BEP referral process. COPD severity was assessed using their Forced Expiratory Volume in One Second (FEV1) as compared to predicted values based on height, age, and sex [4]. FEV1 scores of $80 \%-100 \%$ indicate mild COPD. FEV1 scores between 50\% - 79\% indicate moderate COPD and 49\% or less, severe forms of COPD [4].

\subsubsection{Transient Health States}

We had data pertaining to two transient health states: the 6MWD [39] and the BRPES [40] [41]. The 6MWD is a test of how far a person can walk in a 6 minute period in an ambient temperature in a 30 meter corridor [39]. The average expected score among healthy Canadians between 45 and 85 years of age is 640 meters (SD = 99 meters) and the expected range of scores is 416 - 880 meters [47]. Participants' 6MWD testing was conducted and recorded by a registered BEP respiratory therapist. The BRPES [40] [41] measures self-rated dyspnea that results from perceived effort, strain, discomfort or fatigue during an exercise test conducted on an electronicallystoppable exercise bicycle [48]. Scale values ranged from 0 - 10. A numeric rating of 0 would indicate no breathlessness at all. A score of 5 - 6 indicates severe breathlessness. A score of 10 indicates intolerable breathlessness. BRPES scores were obtained during the final minute of the 6MWD and recorded by a registered BEP respiratory therapist.

\subsection{Data Analysis}

The data for this secondary analysis were collected May through December 2008. Using AMOS Version 21, we tested the goodness-of-fit of Figure 1 and Figure 2 with our study data. To assess goodness-of-fit, we used the Model Chi-square statistic $\left(X^{2}\right)$, Goodness-of-Fit Index (GFI), and Root Mean Square Error of Approximation (RMSEA) [49]. The p-value associated with $X^{2}$ should be equal to or greater than 0.05 . If so, model-implied relationships are a good representation of the sample correlation matrix. The GFI is the percentage of "match" between model-implied relationships and the sample correlation matrix; ideally, this match is 95\%. The RMSEA is an estimate of error between how well model-implied relationships approximate the sample correlation matrix. Reasonable estimates range between 0.05 - 0.08. Cohen's criteria were used to determine path coefficient size [50].

\section{Results}

Table 1 shows the demographic and clinical characteristics of our 87 participants. Only 9.2\% required oxygen. Nearly $40 \%$ of our participants had no other chronic illnesses. As indicated $93.1 \%$ had smoked but all were smoke free for close to a decade. The mean "Physical Functioning" score and the "Physical Health" score were, respectively, 1.8 standard deviations and two-tenths of a standard deviation above the normed score for COPD [38]. "Negative Affect" was 3.4 standard deviations above the norm [38]. The average "6WMD" was 184.62 meters below the expected minimum distance for healthy Canadians between 45 - 85 years of age [47]. The minimum and maximum "BRPES" scores connote "very slight" to "severe" breathlessness.

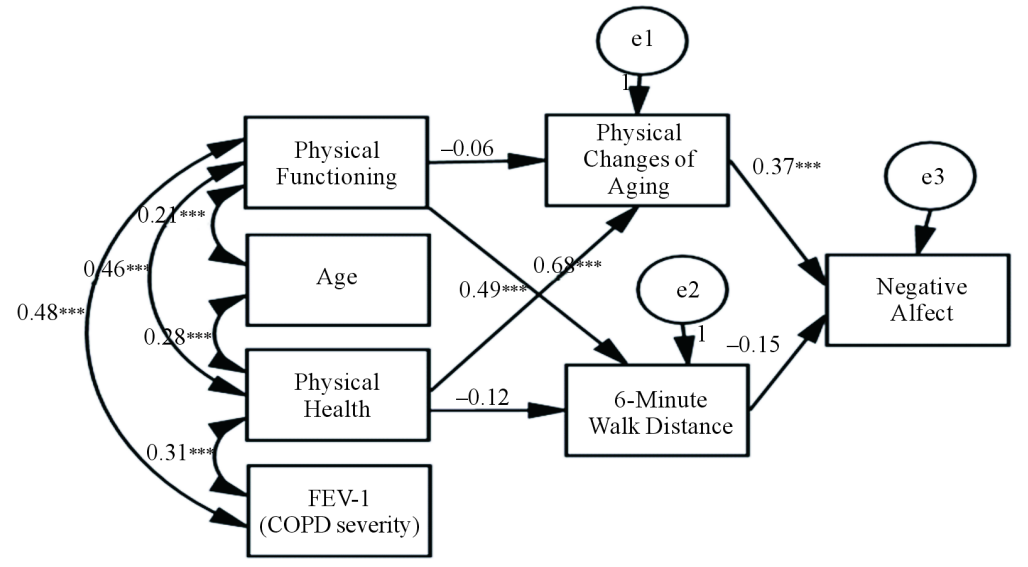

Figure 1. Identity Process Model containing 6-Minute Walk Distance. 


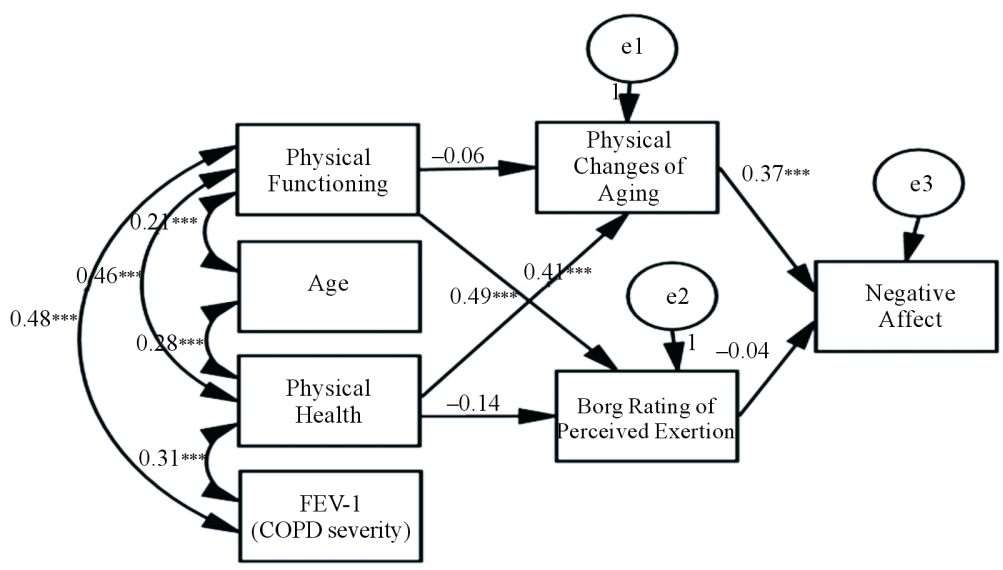

Figure 2. Identity Process Model containing Borg Rating of Perceived Exertion.

Table 1. Participant characteristics $(n=87)$.

\begin{tabular}{|c|c|c|c|}
\hline Participant Characteristic & Number & Percent & Range \\
\hline Female gender & 47 & $54 \%$ & \\
\hline Continuous Flow Oxygen & 8 & $9.2 \%$ & \\
\hline No chronic illnesses & 33 & $37.9 \%$ & \\
\hline 1 - 2 other chronic illnesses & 24 & $27.5 \%$ & \\
\hline 3 - 4 other chronic illnesses & 22 & $25.2 \%$ & \\
\hline 5 - 6 other chronic illnesses & 8 & $9.2 \%$ & \\
\hline Smoking History & 81 & $93.1 \%$ & \\
\hline Mild COPD (FEV-1 80\% or higher) & 8 & $9.2 \%$ & \\
\hline Moderate COPD (FEV-1 50\% - 79\%) & 44 & $50.6 \%$ & \\
\hline Severe COPD (FEV-1 49\% - 31\%) & 25 & $28.7 \%$ & \\
\hline Very Severe COPD (FEV-1 < 30\%) & 10 & $11.5 \%$ & \\
\hline Age & & $67.89 \pm 7.42$ & $47-82$ \\
\hline Number of Years Smoke-free & & $9.83 \pm 11.78$ & $0-53$ \\
\hline FEV-1 & & $53.63 \pm 20.74$ & $19.79-109.27$ \\
\hline Physical Changes of Aging & & $24.28 \pm 4.44$ & $15-34$ \\
\hline Physical Functioning & & $55.47 \pm 22.80$ & $10-95$ \\
\hline Physical Health & & $41.38 \pm 19.63$ & $19.16-62.29$ \\
\hline Negative Affect & & $78.51 \pm 15.10$ & $24-100$ \\
\hline BRPES $^{\mathrm{a}}$ & & $2.13 \pm 1.38$ & $1-6$ \\
\hline $6 \mathrm{MWD}^{\mathrm{b}}$ & & $458.38 \pm 113.67$ & $208-780$ \\
\hline
\end{tabular}

a. BRPES: Borg Rating of Perceived Exertion Scale; b. 6MWD: 6-Minute Walk Distance.

The observed correlation matrix for all study variables is shown in Table 2. "Physical Functioning" and "6MWD" were most strongly correlated. The correlation between "Physical Functioning" and the "Physical Changes of Aging" was negligible. "Physical Health" moderately correlated with the "Physical Changes of Aging". The "Physical Changes of Aging" moderately correlated with "Negative Affect". Higher "FEV-1" scores (lower COPD Severity) was associated with higher "Physical Functioning" and "Physical Health". 
Table 2. Model Variable Correlation Matrix $(\mathrm{n}=87)$.

\begin{tabular}{|c|c|c|c|c|c|c|c|c|}
\hline Variable & Age & $\begin{array}{l}\text { Physical } \\
\text { Functioning }\end{array}$ & $\begin{array}{c}\text { Physical } \\
\text { Health }\end{array}$ & PCA & BRPES & 6MWD & N. Affect & FEV-1 \\
\hline Age & 1 & & & & & & & \\
\hline $\begin{array}{l}\text { Physical } \\
\text { Functioning }\end{array}$ & $-0.148 a$ & 1 & & & & & & \\
\hline Physical Health & $0.315^{* *}$ & $0.474 * * *$ & 1 & & & & & \\
\hline $\mathrm{PCA}^{\mathrm{a}}$ & $0.315^{* *}$ & $0.177 \mathrm{a}$ & $0.475^{* * *}$ & 1 & & & & \\
\hline BRPES $^{\mathrm{b}}$ & $-0.017 \mathrm{a}$ & $-0.478^{* * *}$ & $-0.337 * *$ & $-0.114 a$ & 1 & & & \\
\hline $6 \mathrm{MWD}^{\mathrm{c}}$ & $-0.290 * *$ & $0.631^{* * *}$ & $0.206 a$ & $0.037 \mathrm{a}$ & $-0.391^{* * *}$ & 1 & & \\
\hline N. Affect ${ }^{d}$ & $0.262 *$ & $0.084 a$ & $0.230^{*}$ & $0.363^{* *}$ & $0.001 \mathrm{a}$ & $-0.138 \mathrm{a}$ & 1 & \\
\hline FEV-1 & $0.189 a$ & $0.434 * * *$ & $0.396^{* * *}$ & $0.128 \mathrm{a}$ & $-0.279 * *$ & $0.326^{*}$ & $-0.032 \mathrm{a}$ & 1 \\
\hline
\end{tabular}

a. PCA: Physical Changes of Aging; b. BRPES: Borg Rating of Perceived Exertion Scale; c. 6MWD: 6-Minute Walk Distance. D. N.: Negative.

We used AMOS to test the goodness-of-fit of Figure 1 and Figure 2 with our observed correlation matrix. The 6MWD model shown in Figure 1 fit reasonably well with the study data $\left(X^{2}=18.55, d f=10, p=0.05\right.$; GFI $=0.95$, RMSEA $=0.10$ ). "Physical Functioning" and "Physical Health" were significantly correlated with "Age". This is important as we aimed to examine age-related changes in physical identity. The path from "Physical Functioning" to "6MWD" was strong and statistically significant. The path coefficient from "Physical Functioning" to the "Physical Changes of Aging" was negligible. The statistically significant path coefficient link between "Physical Health" and the "Physical Changes of Aging" was medium in stature. The path coefficient between "Physical Health" and "6MWD" was negligible. The "Physical Changes of Aging" had a moderate positive effect upon "Negative Affect". The impact of "6MWD" upon "Negative Affect" was negligible.

The BRPES model shown in Figure 2 fit the study data best $\left(X^{2}=13.34, d f=10, p=0.21\right.$; GFI $=0.96$, RMSEA = 0.06). The path coefficient between "Physical Functioning" and "BRPES" scores was medium in stature. All other path coefficients were similar to those reported in the 6MWD model.

\section{Discussion}

Establishing links between psychosocial factors that could impact the management of COPD is a research priority [27]. Recent guidelines for pulmonary rehabilitation programs emphasize psychological responses to COPD [51]. COPD has a lengthy disease trajectory and its rising prevalence means that there are growing numbers of people afflicted with it and aging with it. There is a paucity of research on how people with COPD psychologically manage their condition within the context of their own process of aging. Our studied sample consisted of 87 PRP participants aged 47 - 82 who were living with mild, moderate, and severe forms of COPD. Under the auspices of the Identity Process Theory, we explored whether our participants would attribute age-related changes in physical functioning and health to a transient health state versus the physical changes of aging. We also wondered whether transient health attributions, if any, would circumvent participants' negativity toward the physical changes of aging and their propensity for negative affect.

Age-related changes in physical functioning are thought to pose the greatest threat to how people see themselves aging physically. Such changes make people begin to believe that their body is less capable and that they are "old" [6]. Rightly or wrongly, people use transient health attributions to psychologically distance themselves from their own process of aging [5] [6]. Our study found participants used the identity assimilation process in response to age-related changes in their physical functioning. They attributed age-related changes in their physical functioning to perceived dyspnea during a time constrained exercise test and the distance they were able to walk over a 6 minute period. The identity assimilation effect thus occurred regardless of whether a transient health state was rated by BEP participants themselves or a respiratory therapist. Self-managing COPD requires that people work the physical demands of this disease into everyday activities [52] [53]. How people choose to self-manage COPD has much to do with their desires and motives [54]. The non-significance of the path coefficient between physical functioning and the physical changes of aging in this study, in a theoretical sense, signifies our participants' desire to psychological distance themselves from their own process of aging. Among 
people living with incurable illnesses, expecting that one's own aging will bring more declines than improvements can also be a realistic coping mechanism [55]. Such sentiments have been reported among chronically ill middle-aged and older adults [24] [25]. COPD is an incurable illness, and our participants were middle-aged and older adults.

In theory, people attribute age-related changes in their physical identity to the physical changes of aging only when things become unmanageable [5] [6]. The average physical functioning score for our participants was 1.8 standard deviations above the normed score for COPD. The non-significant negative path coefficient between physical functioning and the physical changes of aging suggests that further decrements in functioning would enhance negativity toward this aspect of aging. Based on the significance of physical health to the physical changes of aging and its normed score differential, the normed score for physical functioning is likely the threshold for manageability. These observations underscore the importance of maintaining adequate physical functioning, particularly among older COPD patients, over time. For people with COPD, being physically active is an especially important aspect of everyday life [56] [57]. In the most severe stages of COPD, people strongly desire physical independence [58] [59]. COPD patients themselves point out that ongoing exercise with peers and professional support would help them maintain a physically active lifestyle after a PRP [60]. A principal aim of PRPs is to enhance peoples' participation in day-to-day activities [27] [60]. Decreased functional status, especially in terms of performing activities of daily living, is a common reason for PRP referrals [51]. A large component of PRPs consists of helping patients develop COPD-specific functional exercise routines to maintain physical function [4] [51] [61]-[63]. Although there is considerable variation in the duration of PRPs, they are time-limited programs. The BEP for our participants is 8 weeks long. A number of researchers are working toward establishing the optimal duration of PRPs to enhance exercise capacity and maintenance [51] [64]-[67]. It has been recommended that PRP participants be observed completing routine activities in their homes to better understand how to transfer gains in their capacity for exercise into day-to-day routines [51]. This would permit trialing activities in the home like those introduced in PRPs and discussing these experiences before program completion [68]. Others have suggested making referrals to community-based exercise facilities and adding community-based exercise programs after PRPs as a means to help maintain a physically active lifestyle [68]] [69]. Teaching COPD patients how to communicate what they need from family and friends to stay as active as possible after PRPs is also important [68]. Researchers are exploring the use of portable activity monitors to get immediate feedback on activity performance [65] and the role of family in encouraging physical activity during PRPs [70]. Knowing how to best help PRP participants maintain a physically active lifestyle is a key priority among practitioners and researchers. Our findings speak to such sentiments specifically in relation to circumventing negativity toward aging physically.

Two recent meta-analyses indicate that structured exercise programs that enhance physical functioning are more effective than are psychological or life-style interventions in terms of reducing symptoms of depression and anxiety among PRP participants [61] [62]. Other psychological benefits of structured exercise programs include having others to relate to [68], feeling less socially isolated and more motivated [69], and less negative perceptions about the psychosocial impact of COPD [70]. In keeping with the IPT, our findings suggest that having manageable age-related changes in physical functioning circumvents negative affect. Negative affect, in our case, refers to feeling downhearted and blue, nervous, or down in the dumps. The lesser propensity for negative affect that we had observed on two occasions among our studied sample further speaks to the psychological importance of maintaining a physically active lifestyle post-PRP.

Our participants used the identity accommodation process in response to age-related changes in physical health. The psychological benefit of participants' selective use of accommodation was an enhanced perception of the physical changes of aging and a lesser propensity for negative affect. In keeping with the IPT this also means that participants found age-related changes in their physical health unmanageable. Physical health scores were, on average, only 2/10 of a standard deviation above what we had expected and had a far narrower range than did physical functioning scores (43.13 versus 85). Participants' SF36 data were collected right after the BEP ended, a time during which one would reasonably expect physical health scores to be the highest after a PRP. Participants' remarkably poorer perceptions of overall physical health draw attention to the importance of general health promotion.

Some researchers argue that COPD patients are not necessarily aware of how to promote their overall physical health apart from attending pulmonary rehabilitation and stopping smoking [71] [72]. The most common PRP interventions apart from exercise are broad but focus on disease management through relaxation techniques, 
skills training, and problem-solving techniques, and general education about managing infections and exacerbations, and respiratory medications [61] [62]. Other foci consist of enhancing self-efficacy, symptoms and emotions management, and goal setting to better self-manage COPD [73]. General self-management techniques not specific to COPD tend to pertain to healthy food intake and leisure activities [51]. Notwithstanding others consider techniques for managing stress and anxiety, traveling, intimacy and sleep hygiene important extra-pulmonary features for promoting a healthy lifestyle [74]. PR is currently defined as a comprehensive intervention based on a thorough patient assessment followed by patient-tailored therapies [75]. Participant-tailored interventions in PRPs require individualized assessments to address the complex extra-pulmonary needs of COPD patients [73]. BEP participants had access to a respiratory physiologist and a physiotherapist. BEP program activities were delivered at the group level, and while participants met with rehabilitation staff individually several times throughout the program to discuss their personal condition, participant-tailored interventions are somewhat limited.

\section{Limitations}

Our modest sample size prevents us from generalizing beyond the studied sample. The cross-sectional nature of our data does not establish causes and effects. Making peer observations and comparisons can instill in COPD patients the belief that trying respiratory-related physical limitations are to be expected with age [76]. This may explain participants' attributing age-related changes in physical functioning to transient health states as opposed to the physical changes of aging. We lacked a measure of a third aspect of physical identity, namely physical appearance. Few studies have examined perspectives on changing physical appearance among COPD patients [11] [19] [28]. Up to 30\% of COPD patients experience muscle wasting and increases in body fat mass [51]. How people with COPD interpret changes in their physical appearance in relation to aging physically bodes additional future empirical attention. In future, we will collect data from a larger sample of PRP participants over time such as before and after pulmonary rehabilitation programs to determine whether identity process preferences among people with COPD change. A larger sample should permit comparisons of identity process preferences among PRP participants who rank themselves above, at, and below the normed score for physical functioning. Our study sample wholly consists of PRP participants at one geographic region diagnosed with COPD. Recruiting attendees from other programs and who are also managing other lung diseases like asthma will provide a more rigorous test of the IPT. AMOS can be used again as it permits examining attribution process preferences across multiple normed score and pulmonary disease groups [49]. Recruiting non-attendees will help us rule out the confounding effect of age-inclusivity upon attribution process preferences. Using Whitbourne's Physical and Cognitive Change Scale [77] will afford exploring attribution process preferences for physical appearance. All such research will establish the importance understanding what it is like to be aging with COPD and how this affects the mental health of patients living with this disease.

\section{Acknowledgements}

All authors are thankful for having received financial supports from the Caritas Health Foundation, Grant \#981.

\section{References}

[1] Brandt, C. (2013) Study of Older Adults' Use of Self-Regulation for COPD Self-Management Informs an EvidenceBased Patient Teaching Plan. Rehabilitation Nursing, 38, 11-23. http://dx.doi.org/10.1002/rnj.56

[2] Stridsman, C., Lindenberg, A. and Skar, L. (2013) Fatigue in Chronic Obstructive Pulmonary Disease: A Qualitative Study of People's Experiences. Scandinavian Journal of Caring Sciences, 28, 130-138. http://dx.doi.org/10.1111/scs.12033

[3] Chen, Y., Stewart, P., Dales, R., Johansen, H., Bryan, S. and Taylor, G. (2005) Changing Age-Patterns of Hospitalization Risk of Chronic Obstructive Pulmonary Disease in Men and Women in Canada. Age and Ageing, 34, 373-377. http://dx.doi.org/10.1093/ageing/afi092

[4] O’Donnell, D.E., Hernandez, P., Kaplan, A., Aaron, S., Bourbeau, J., Marciniuk, D., et al. (2008) Canadian Thoracic Society Recommendations for Management of Chronic Obstructive Pulmonary Disease-2008 Update—Highlights for Primary Care. Canadian Respiratory Journal, 15, 1A-8A. http://www.respiratoryguidelines.ca/COPD-2008-update

[5] Whitbourne, S.K., Sneed, J.R. and Skultety, K.M. (2002) Identity Processes in Adulthood: Theoretical and Methodo- 
logical Challenges. Identity: An international Journal of Theory and Research, 2, 29-45. http://dx.doi.org/10.1207/S1532706XID0201_03

[6] Whitbourne, S.K. and Collins, K.J. (1998) Identity Processes and Perceptions of Physical Functioning in Adults: Theoretical and Clinical Implications. Psychotherapy, 35, 519-530. http://dx.doi.org/10.1037/h0087666

[7] Low, G., Ross, C., Stickland, M., Wilson, D. and Wong, E. (2013) Perspectives of Aging among Persons Living with Chronic Obstructive Pulmonary Disease. Western Journal of Nursing Research, 35, 884-904. http://dx.doi.org/10.1177/0193945913478844

[8] Ek, K. and Ternestedt, B.M. (2008) Living with Chronic Obstructive Pulmonary Disease at End of Life: A Phenomenological Study. Journal of Advanced Nursing, 62, 470-478. http://dx.doi.org/10.111/j.1365-2648.2008.04611.x

[9] Kanervisto, M., Kaistila, T. and Paavilainen, E. (2007) Severe Chronic Obstructive Pulmonary Disease in a Family’s Everyday Life in Finland: Perceptions of People with Chronic Obstructive Pulmonary Disease and their Spouses. Nursing and Health Sciences, 9, 40-47. http://dx.doi.org/10.1111/j.1442-2018.2007.00303.x

[10] Fraser, D.D., Kee, C.C. and Minick, P. (2006) Living with Chronic Obstructive Pulmonary Disease: Insider’s Perspectives. Journal of Advanced Nursing, 55, 550-558. http://dx.doi.org/10.1111/j.1365-2648.2006.03946.x

[11] Gullick, J. and Stainton, C. (2008) Living with Chronic Obstructive Pulmonary Disease: Developing Conscious Body Management in a Shrinking Life-World. Journal of Advanced Nursing, 6, 605-614. http://dx.doi.org/10.1111/j.1365-2648.2008.04823.x

[12] Wilson, D., Ross, C., Goodridge, D., Davis, P., Landreville, A. and Roebuck, D. (2009) The Care Needs of Community-Dwelling Seniors Suffering from Advanced Chronic Obstructive Pulmonary Disease. Canadian Journal on Aging, 27, 347-357. http://dx.doi.org/10.3138/cja.27.4.347

[13] Chen, K.H., Chen, M.L., Lee, S., Cho, H.Y. and Weng, L.C. (2008) Self-Management Behaviors for Patients with Chronic Obstructive Pulmonary Disease: A Qualitative Study. Journal of Advanced Nursing, 64, 595-604. http://dx.doi.org/10.1111/j.1365-2648.2002.04821.x

[14] Cicutto, L.C., Brooks, D. and Henderson, K. (2004) Self-Care Issues from the Perspectives of Individuals with Chronic Obstructive Pulmonary Disease. Patient Education and Counseling, 55, 168-176. http://dx.doi.org/10.1016.j.pec.2003.08.012

[15] de Sousa Pinto, J.M., de Sousa Vieiera, L.J.E. and Nations, M.K. (2008) Breath of Life: Experience with Chronic Obstructive Pulmonary Disease in Urban Poverty in Fortaleza Ceara, Brazil. Journal of Public Health, 24, 2809-2818. http://dx.doi.org/10.1590/S0102-311X2008001200009

[16] Harris, D., Hayter, M. and Allender, S. (2008) Improving the Uptake of Pulmonary Rehabilitation in Patients with COPD: Qualitative Study of Experiences and Attitudes. British Journal of General Practice, 58, 703-710. http://dx.doi.org/10.3399/bjgp08X342363

[17] Seamark, D.A., Blake, S.D., Seamark, C.J. and Halpin, D.M.G. (2004) Living with Severe Chronic Obstructive Pulmonary Disease (COPD): Perceptions of Patients and their Carers-An Interpretive Phenomenological Analysis. Palliative Medicine, 18, 619-625. http://dx.doi.org/10.1191/0269216304pm928oa

[18] Barnett, M. (2005) Chronic Obstructive Pulmonary Disease: A Phenomenological Study of Patients’ Experiences. Journal of Clinical Nursing, 14, 805-812. http://dx.doi.org/10.1111/j.1365-2702.2005.01125.x

[19] Elofsson, L.C. and Ohlen, J. (2004) Meanings of Being Old and Living with Chronic Obstructive Pulmonary Disease. Palliative Medicine, 18, 611-618. http://dx.doi.org/10.1191/0269216304pm922oa

[20] Walker, C.A. (2002) Transformative Aging: How Mature Adults Respond to Growing Older. The Journal of Theory Construction \& Testing, 6, 109-116.

[21] Freund, A.M. and Smith, J. (1999) Content and Function of the Self-Definition of Old and Very Old Age. Journals of Gerontology, Series B Psychological Sciences, 54B, 55-67. http://dx.doi.org/10.1093/geronb/54B.1.P55 http://psychsocgerontology.oxfordjournals.org/content/54B/1/P55.full.pdf

[22] Smith, J. and Freund, A.M. (2002) The Dynamics of Possible Selves in Old Age. Journals of Gerontology, Series B Psychological Sciences, 57B, 492-500. http://psychsocgerontology.oxfordjournals.org/content/57B/6/P492.full.pdf

[23] Timmer, E., Steverink, N. and Dittmann-Kohli, F. (2002) Cognitive Representations of Future Gains, Maintenance, and Losses in the Second Half of Life. International Journal of Aging \& Human Development, 55, 321-339. http://dx.doi.org/10.1177/009141500205500401

[24] Wurm, S., Tomasik, M.J. and Tesch-Romer, C. (2008) Serious Health Events and Their Impact on Changes in Subjective Health and Life Satisfaction: The Role of Age and a Positive View on Ageing. European Journal on Ageing, 5, 117-127. http://dx.doi.org/10.1007/s10433-008-0077-5

[25] Andersson, M., Hallberg, I.R. and Edberg, A.K. (2008) Old People Receiving Municipal Care, Their Experiences of What Constitutes a Good Life in the Last Phase of Life: A Qualitative Study. International Journal of Nursing Studies, 
45, 818-828. http://dx.doi.org/10.1016/j.ijnursstu.2007.04.003

[26] Simpson, E. and Jones, M. (2013) An Exploration of Self-Efficacy and Self-Management in COPD Patients. British Journal of Nursing, 22, 1105-1109. http://dx.doi.org/10.12968/bjon.2013.22.19.1105

[27] von Leupoldt, A., Fritzsche, A., Trueba, A.F., Meuret, A. and Ritz, T. (2012) Behavioral Medicine Approaches in Chronic Obstructive Pulmonary Disease. Annals of Behavioral Medicine, 44, 52-65. http://dx.doi.org/10.1007/s12160-012-9348-7

[28] O’Neill, E.S. (2002) Illness Representations and Coping of Women with Chronic Obstructive Pulmonary Disease. Heart \& Lung, 31, 295-302. http://dx.doi.org/10.1067/mhl.2002.123712

[29] Levy, B.R. and Meyers, L.M. (2005). Relationship between Respiratory Mortality and Self-Perceptions of Aging. Psychology and Health, 20, 535-564. http://psycnet.apa.org/doi/10.1080/14768320500066381

[30] Ito, K. and Barnes, P.J. (2009) COPD as a Disease of Accelerated Lung Aging. Chest, 135, 173-180. http://dx.doi.org/10.1378/chest.08-1419

[31] MacNee, W. (2009) Accelerated Lung Aging: A Novel Pathogenic Mechanism of Chronic Obstructive Pulmonary Disease (COPD). Biochemical Society Transactions, 37, 819-823. http://dx.doi.org/10.1042/BST0370819

[32] Papaioannou, A.I., Rossios, C., Kostikas, K. and Ito, K. (2013) Can We Delay the Accelerated Lung Aging in COPD? Anti-Aging Molecules and Interventions. Current Drug Targets, 14, 149-157. http://dx.doi.org/10.2174/1389450111314020003

[33] Sneed, J.R. and Whitbourne, S.K. (2005) Models of the Aging Self. Journal of Social Issues, 61, 375-388. http://dx.doi.org/10.1111/j.1540-4560.2005.00411.x

[34] Sneed, J.R. and Whitbourne, S.K. (2003) Identity Processing and Self-Consciousness in Middle and Older Adulthood. Journals of Gerontology, Series B Psychological Sciences, 58B, 313-319. http://dx.doi.org/10.1093/geronb/58.6.P313

[35] Barniuk, A. and Sheffield, D. (2011) The Efficacy of Psychologically Based Interventions to Improve Anxiety, Depression and Quality of Life in COPD: A Systematic Review and Meta-Analysis. Patient Education and Counselling, 83, 29-36. http://dx.doi.org/10.1016/j.pec.2010.04.010

[36] Fritzsche, A., Clamor, A. and von Leupoldt, A. (2011) Effects of Medical and Psychological Treatment of Depression in Patients with COPD—A Review. Respiratory Medicine, 105, 1422-1433. http://dx.doi.org/10.1016/j.rmed.2011.05.014

[37] Zhang, M.W.B., Ho, R.C.M., Chung, M.W.L., Fu, E. and Mak, A. (2011) Prevalence of Depressive Symptoms in Patients with Chronic Obstructive Pulmonary Disease. General Hospital Psychiatry, 33, 217-233. http://dx.doi.org/10.1016/j.genhosppsych.2011.03.009

[38] Ware, J. and Kozinski, M. (2007) SF-36® Physical and Mental Health Summary Scales: A Manual for User’s of Version 1. 2nd Edition, Quality Metric Incorporated, Lincoln.

[39] American Thoracic Society (2002) ATS Statement: Guidelines for the Six-Minute Walk Test. American Journal of Critical Care Medicine, 166, 111-117. https://www.thoracic.org/statements/resources/pfet/sixminute.pdf http://dx.doi.org/10.1164/ajrccm.166.1.at1102

[40] Borg, G.A.V. (1982) Psychophysical Bases of Perceived Exertion. Medicine and Science in Sports and Exercise, 14, 377-381. http://dx.doi.org/10.1249/00005768-198205000-00012

[41] Borg, G.A.V., Hassmen, P. and Lagerstrom, M. (1987) Perceived Exertion Related to Heart Rate and Blood Lactate during Arm and Leg Exercises. European Journal of Applied Physiology, 65, 679-685. http://dx.doi.org/10.1007/BF00424810

[42] Moorer, P., Surrmeijer, P.B.M., Foets, M. and Molenaar, I.W. (2001) Psychometric Properties of the RAND-36 among Three Chronic Diseases (Multiple Sclerosis, Rheumatic Diseases and COPD) in the Netherlands. Quality of Life Research, 10, 637-645. http://dx.doi.org/10.1023/A:1013131617125

[43] Laidlaw, K., Power, M.J. and Schmidt, S. (2007) The Attitudes to Aging Questionnaire (AAQ): Development and Psychometric Properties. International Journal of Geriatric Psychiatry, 22, 367-279. http://dx.doi.org/10.1002/gps.1683

[44] Kalfoss, M., Low, G. and Molzahn, A.E. (2010) Reliability and Validity of the Attitudes to Aging Questionnaire for Canadian and Norwegian Older Adults. Scandinavian Journal of Caring Sciences, 24, 75-85. http://dx.dio.org/10.111/j.1471-6712.2010.00786.x

[45] Bryant, C., Bei, B., Gilson, K., Komiti, A., Jackson, H. and Judd, F. (2012) The Relationship between Attitudes to Aging and Physical and Mental Health in Older Adults. International Psychogeriatrics, 24, 1674-1683. http://dx.doi.org/10.1017/S1041610212000774

[46] Lucas-Carrasco, M., Laidlaw, K., Gonez-Benito, J. and Power, M.J. (2013) The Suitability of the Attitudes Ageing (AAQ) for Spanish Older Adults. International Psychogeriatrics, 25, 490-499. 
http://dx.doi.org/10.1017/S1041610212001809

[47] Hill, K., Wickerson, L.M., Woon, L.J., Abady, A.H., Overend, T.J., Goldstein, R.S., et al. (2011) The 6-Minute Walk Test: Responses in Healthy Canadians Age 45-85 Years. Applied Physiology, Nutrition, and Metabolism, 36, 643-649. http://dx.doi.org/10.1139/H11-075

[48] American College of Sports Medicine (2015) Perceived Exertion. https://www.acsm.org/docs/current-comments/perceivedexertion.pdf

[49] Byrne, B.M. (2010) Structural Equation Modeling with AMOS: Basic Concepts, Applications, and Programming. Lawrence-Erlbaum, Mahwah.

[50] Cohen, J. (1988) Statistical Power Analysis for the Behavioral Sciences. Lawrence-Erlbaum, Hillside.

[51] Spruit, M.A., Singh, S.J., Garvey, C., ZuWallack, R., Nici, L., Rochester, C., et al. (2013) An Official American Thoracic Society/European Respiratory Society Statement: Key Concepts and Advances in Pulmonary Rehabilitation. American Journal of Respiratory \& Critical Care Medicine, 188, e13-e64. http://dx.doi.org/10.1164/rccm.201309-1634ST

[52] Bourbeau, J., Nault, D. and Dang-Tan, T. (2004) Self-Management and Behavior Modification in COPD. Patient Education and Counseling, 52, 271-277. http://doi.org/10.1016/S0738-3991(03)00102-2

[53] Cramm, J.M. and Nieboer, A.P. (2012) Self-Management Abilities, Physical Health, and Depressive Symptoms among Patients with Cardiovascular Disease, Chronic Obstructive Pulmonary Disease, and Diabetes. Patient Education and Counseling, 87, 411-415. http://dx.doi.org/10.1016/j.pec.2011.12.006

[54] Simpson, A.C. and Rocker, G.M. (2008) Advanced Chronic Obstructive Pulmonary Disease: Advanced Models of Care. Quality Journal of Medicine, 101, 697-704. http://dx.doi.org/10.1093/qjmed/hcn087

[55] Sarkisian, C.A., Hays, R.D., Berry, S. and Mangione, C.M. (2002) Development, Reliability, and Validity of the Expectations Regarding Aging (ERA-38) Survey. Gerontologist, 42, 534-542. http://dx.doi.org/10.1093/geront/42.4.534

[56] Kline-Leidy, N. (2007) Subjective Measurement of Activity in Chronic Obstructive Pulmonary Disease. COPD: Journal of Chronic Obstructive Pulmonary Disease, 4, 243-249. http://dx.doi.org/10.1080/15412550701480414

[57] Miravitlles, M., Anzueto, A., Legnani, D., Forstmeier, L. and Fargel, M. (2007) Patient's Perspectives of Exacerbations of COPD—The PERCEIVE Study. Respiratory Medicine, 101, 453-460.

[58] Wilson, D., Ross, C., Goodridge, D., Davis, P., Landreville, A. and Roebuck, D. (2009) The Care Needs of Community-Dwelling Seniors Suffering from Advanced Chronic Obstructive Pulmonary Disease. Canadian Journal on Aging, 27, 347-357. http://dx.doi.org/10.3138/cja.27.4.347

[59] Williams, V., Bruton, A., Ellis-Hall, C. and McPherson, K. (2007) What Really Matters to Patients Living with Chronic Obstructive Pulmonary Disease? An Exploratory Study. Chronic Respiratory Disease, 4, 77-85. http://dx.doi.org/10.1177/1479972307078482

[60] Hogg, L., Grant, A., Garrod, R. and Fiddler, H. (2012) People with COPD Perceive Ongoing, Structured, and Socially Supportive Exercise Opportunities to be Important for Maintaining an Active Lifestyle Following Pulmonary Rehabilitation: A Qualitative Study. Journal of Physiotherapy, 58, 189-195. http://dx.doi.org/10.106/S1836-9553(12)70110-8

[61] Coventry, P.A., Bower, P., Keyworth, C., Kenning, C., Knopp, J., Garrett, C., et al. (2013) The Effect of Complex Interventions on Depression and Anxiety in Chronic Obstructive Pulmonary Disease: Systematic Review and MetaAnalysis. PLoS ONE, 8, 1-19. http://dx.doi.org/10.1371/journal.pone.0060532

[62] Panagioti, M., Scott, C., Blakemore, A. and Coventry, P.A. (2014) Overview of the Prevalence, Impact, and Management of Depression and Anxiety in Chronic Obstructive Pulmonary Disease. International Journal of COPD, 9, 12891306. http://dx.doi.org/10.2147/COPD. S72073

[63] Egan, C., Deering, B.M., Blake, C., Fullen, M.B.M., McCormack, N.M., Spruit, M.A., et al. (2012) Short Term and Long Term Effects of Pulmonary Rehabilitation on Physical Activity in COPD. Respiratory Medicine, 106, 1671-1679. http://dx.doi.org/10.1016/j.rmed.2012.08.016

[64] Beauchamp, M.K., Janaudis-Ferreira, T., Goldstein, R. and Brooks, D. (2011) Optimal Duration of Pulmonary Rehabilitation for Individuals with Chronic Obstructive Pulmonary Disease-A Systematic Review. Chronic Respiratory Disease, 8, 129-140. http://dx.doi.org/10.1177/1479972311404256

[65] Cruz, J., Brooks, D. and Marques, A. (2014) Impact of Feedback on Physical Activity Levels of Individuals with Chronic Obstructive Pulmonary Disease during Pulmonary Rehabilitation: A Feasibility Study. Chronic Respiratory Disease, 11, 191-198. http://dx.doi.org/10.1177/1479972314552280

[66] Goldstein, R.S., Hill, K., Brooks, D. and Dolmage, T.E. (2012) Pulmonary Rehabilitation: A Review of the Recent Literature. Chest, 142, 738-749. http://dx.doi.org/10.1378/chest.12-0188

[67] Wilson, A.M., Browne, P., Olive, S., Clark, A., Galey, P., Dix, E., et al. (2015) The Effects of Maintenance Schedules following Pulmonary Rehabilitation in Patients with Chronic Obstructive Pulmonary Disease: A Randomized Control 
Trial. BMJ Open, 5, e005921. http://dx.doi.org/10.1136/bmjopen-2014-005921

[68] Meis, J.J.M., Bosma, C.B., Spruit, M.A., Franssen, F.M.E., Janssen, D.J.A., Teixeira, P.J., et al. (2014) A Qualitative Assessment of COPD Patients' Experiences of Pulmonary Rehabilitation and Guidance by Healthcare Professionals. Respiratory Medicine, 108, 500-510. http://dx.doi.org/10.1016/j.rmed.2013.11.001

[69] Desveaux, L., Rolfe, D., Beauchamp, M., Goldstein, R. and Brooks, D. (2014) Participant Experiences of a Community-Based Maintenance Program Post-Pulmonary Rehabilitation. Chronic Respiratory Disease, 11, 23-30. http://dx.doi.org/10.1177/1479972313516880

[70] Marquez, A., Jacombe, C., Cruz, J., Gabriel, R., Brooks, D. and Figueiredo, D. (2015) Family-Based Psychosocial Support and Education as Part of Pulmonary Rehabilitation in COPD. Chest, 147, 662-672. http://dx.doi.org/10.1378/chest.14-1488

[71] Caress, A., Luker, K. and Chalmers, K. (2010) Promoting the Health of People with Chronic Obstructive Pulmonary Disease: Patients' and Carers' Views. Journal of Clinical Nursing, 19, 564-573. http://dx.doi.org/10.1111/j.1365-2702.2009.02982.x

[72] Dobrowolska, B., Mazurek, H., Slursarska, B., Zarzycka, D., Charzynska, M. and Cuber, T. (2014). Health-Promoting Activities Performed by Nurses for Patients with COPD. Pneumonologiai Alergologia Polska, 82, 125-132. http://dx.doi.org/10.5603/PiAP.2014.0018

[73] Spruit, M.A., Pitta, F., Garvey, C., ZuWallack, R.L., Roberst, C.M., Collins, E.G., et al. (2014) Differences in Content and Organizational Aspects of Pulmonary Rehabilitation Programmes. European Respiratory Journal, 43, 1326-1337. http://dx.doi.org/10.1183/09031936.00145613

[74] Nault, D. and Sedeno, M. (2006) Reference Guide for Patient Education: Educating COPD Patients Using the Self-Management Program "Living Well with COPD”. Montreal Chest Institute of the McGill University Health Center, Montreal. http://www.livingwellwithcopd.com

[75] Singh, S.J., ZuWallack, R.L., Garvey, C. and Spruit, M.A. (2013) Learn From the Past and Create the Future: The 2013 ATS/ERS Statement on Pulmonary Rehabilitation. European Respiratory Journal, 42, 1169-1174. http://dx.doi.org/10.1183/09031936.00207912

[76] Habraken, J.M., Pols, J., Bindels, P.J.E. and Willems, D.L. (2008) The Silence of Patients with End-Stage COPD: A Qualitative Study. British Journal of General Practice, 58, 844-849. http://dx.doi.org/10.3399/bjgp08X376186

[77] Whitbourne, S.K. (1996) The Aging Individual: Physical and Psychological Perspectives. Springer, New York. 